Acuña-Rivera, M., Brown, J., \& Uzzell, D. (2014, in press). Risk perception as mediator in perceptions of neighbourhood disorder and safety about victimization. Journal of Environmental Psychology. DOI: 10.1016/j.jenvp.2014.05.002.

\title{
Risk perception as mediator in perceptions of neighbourhood disorder and safety about victimization
}

\section{Marcela Acuña-Rivera, Jennifer Brown and David Uzzell}

\begin{abstract}
This paper tested a new conceptual model suggesting that risk perception is a significant mediator between perceived neighbourhood disorder and a sense of (un)safety. Three components of risk perception were evaluated: perceived vulnerability, controllability and probability of occurrence of specific offences. Using photo-simulation, three places with different levels of physical and social disorder were created and 120 British students rated the level of disorder, risk and safety of each place. Results showed that risk perception partially mediated the relationship between perceived disorder and safety. Perceived vulnerability was the strongest predictor and mediator in all three places but most significantly in the degraded place. Findings indicated that the more disordered a place is perceived the more a person relies on the perception of risk to estimate how safe she or he might be. Investigating the interpretive processes that occur when people estimate risk and safety, is crucial.
\end{abstract}

Keywords: neighbourhood disorder; risk perception; perceived vulnerability; controllability; acceptability; safety

\section{Introduction}

Vandalised neighbourhoods, covered with graffiti and litter, have been said to increase antisocial behaviour, lack social control and are precipitant to crime. This in turn, evokes anxiety, fear and unsafe feelings amongst residents and outsiders, even when actual crime is low (Brown, Perkins \& Brown, 2004; Brunton-Smith \& Sturgis, 2011; Skogan, 1990; Taylor, 1987; Wilson \& Kelling, 1982). This proposition has 
been criticised for its conceptual and methodological vagueness, physical determinism, and omission of a psychosocial dimension estimating neighbourhood disorder and safety (Chadee, Austen \& Ditton, 2007; Hale, 1996; Farrall, Grey \& Jackson, 2007; Wilcox-Roundtree \& Land, 1997).

An alternative position argues that both perceived disorder and fear of crime are co-determined by unobserved causes and social meanings associated with environmental cues. Factors such as collective efficacy and community cohesion (Pitner, Yu \& Brown, 2012; Sampson \& Raudenbush, 1999), social structure, neighbourhood composition and prior beliefs, informed by stereotypes and stigma (Body-Gendrot, 2009; Sampson \& Raudenbush, 2004, 2005) are thought to shape perceptions of disorder and other reactions to crime such as fear and unsafe feelings. Some researchers have found that racial, ethnic and class composition (Sampson, 2009), and poverty (Franzini, O’Brien-Caughy, Murray-Nettles, \& O’Campo, 2008) are more powerful predictors than observed neighbourhood disorder and argue that minority-migrant groups living in isolation and poverty, have been historically stigmatised and associated with neighbourhood disorder and crime.

There is also research examining the reciprocal relationship whereby perceived disorder influences fear of crime and the latter heightens public's sensitivity to disordered places (Jackson, Gray \& Brunton-Smith, 2010). Such causal reciprocity, we suggest, however socially constructed (cf Jackson and colleagues) needs to be interpreted on the basis of an individual's past experience (direct or indirect) and cognitive and emotional processes. Whilst there have been attempts to integrate psychological and sociological accounts to explain fear of crime (Jackson, 2008; 
Jackson, Allum \& Gaskell, 2006) little by way of empirical evidence is available to support this conceptual stance; an omission this paper seeks to redress.

Here, we focus on and extend the fear-risk paradox concept which suggests that fear seems to be greatest amongst those who perceive themselves to be most vulnerable, when in fact they are at least objective risk of victimisation such as women, the elderly and racial minorities (Wyant, 2008). Researchers using this approach pointed out that risk perception, sensitivity to risk and vulnerability are better predictors of fear of crime. Broadly speaking, there are two research trends attempting to account for the fear-risk paradox: one argues that a person's demographic and physical characteristics and their perception of the offence, the risk and its seriousness, determine their vulnerability and sensitivity to crime (Killias, 1990; Semmens, 2004; Warr, 1984, 1987).

The second proposes that the fear-risk paradox is an emotional reaction that is elicited by interactive dynamics between personal attributes, interpretive processes and physical-social and environmental cues that relate to symbols of crime, the potency of the danger and some aspects of personal harm or loss (Ferraro, 1995; Garofalo,1981; LaGrange, Ferraro \& Supancic, 1992). Garofalo, for example, focused on psychological processes and stated that a person’s demographic attributes, beliefs, attitudes, experience, and overall lifestyle, influence the image of crime held by a person, which in turn affects her/his assessment of risk. Ferraro, on the other hand, argued that the recognition of a potential danger, which he names perceived risk, is necessary to elicit fear. For him, people react to crime in terms of both the situational context and the personal meanings attached to each type of crime, which in turn are 
derived from the social interaction with others (including knowledge from experts and culture) and the physical environment. Therefore, people’s perceptions of risk and behaviour need to be investigated within the context where they occur.

Even though interactionist models represent an advance on the deterministic approaches such as the broken windows theory (Wilson, 1975; Wilson \& Kelling, 1982) and the incivilities thesis (Hunter, 1978; Skogan, 1990), the fear-risk paradox is, itself, too speculative and has had insufficient empirical support; hence, its explanatory power remains limited. Critiques stress that the fear-risk paradox has not progressed due to the lack of a more psychological framework that helps to define and explain the perceptual and interpretive processes that occur when people evaluate places and estimate risks (Chadee, Austen \& Ditton, 2007; Jackson, 2009). More importantly, they do not consider the importance of the interaction between psychological, social and environmental components that influence the way people react to crime. As noted by Ferraro (1995), such interaction may adjust pre-existent conceptions and reactions towards crime, risk and fear i.e. create a dynamic and shifting risk assessment. Thus the addition of cognitive, affective and socio-cultural processes that occur when people evaluate places is still required.

Building upon the conceptual premises and empirical contributions from both 'fear of crime' and risk analysis approaches, this paper introduces a new conceptual model to explain the relationship between environmental variables (physical and social disorder), risk perception and sense of safety in residential areas. Whilst neighbourhood perceptions of physical and social disorder are necessary conditions but in and of themselves are insufficient to explain feelings of fearfulness and 
insecurity. Rather, the perception of risks is associated with people in places and it is this, we say, influences assessments of safety and fear of possible victimisation from crime. This paper is organised in the following manner. First, we present the conceptual model proposed and its main components, explaining how each one of them contributes to perceptions of safety. We then describe the method used to test the model and critically assess the results obtained. We conclude by discussing the implications of our study in light of current and future research.

\subsection{The model}

Our model hypothesises that if a place has been appraised as having a certain level of disorder then a second appraisal of the place is undertaken by the perceiver in terms of the risk it may pose to them. Therefore, the relationship between perceived disorder and sense of safety is thought to be mediated by an assessment of risk. For a fuller explanation of the model, the following sections will describe each component and how they are conceptualised.

The key components of the model are the individual and the contextual factors that influence the way a person perceives places and estimates risk and safety such as socio-demographic characteristics of the perceiver, personal dispositions and traits, affects and experience with similar places, motives, the situation itself, and a person's socio-cultural background. These factors are constantly interacting within and between the other components of the model.

Researchers investigating neighbourhood disorder and incivilities have argued that people evaluate places in terms of, amongst other things, physical and social 
incivilities and that these have an effect on crime, fear and perceived safety (Cozens, Hillier \& Prescott, 2001; Doran \& Lees, 2005; Perkins \& Taylor, 1996). According to this research, insufficient lighting, novelty, and high density, tend to make people feel more unsafe (Painter, 1996); green foliage density and maintenance also have been found to have an effect on fear and perceived safety (Kuo, Bacaioca \& Sullivan, 1998; Kuo \& Sullivan, 2001). In a study using photo-simulation, Pitner and Astor (2008) examined the effect that physical incivilities had in children's perceptions and attributions of harm in residential areas. They concluded that, as expected, physical disorder influenced children's perceptions of danger and safety. A major concern is that the authors did not investigate further the effect that, for instance, experience (direct or indirect), inferred social disorder and estimations of risk had in children's reasoning. In their study, participants referred to the likely harm that dangerous people living there may inflict on them, especially in the most decayed areas. For us, both instances are a sign of children's inferences and estimations of risk, personal vulnerability and coping responses to a (inferred) likely danger rather than a direct consequence of the physical characteristics of the neighbourhoods. Also, personal values and morals seem to have influenced children's decision making when presented with provocation scenarios, as the majority of children condemned retribution and violence irrespective of the physical characteristics of the places (p. 333).We argue that it is not only the presence of incivilities but also other psychosocial and contextual attributes that are significant to perceptions of safety. Investigating the interpretive processes that occur when children estimate safety and risk is crucial. 
Other scholars concur with the idea that overall appearance of places, or likeability, evokes favourable or unfavourable reactions (e.g. nice, good, awful) and point out that if one's feelings towards an event (or place) are favourable then the risks will be judged as low and the benefits high. Hence, the more liked a place, the less disordered, risky, and unsafe it will be perceived (Alkahami \& Slovic, 1994; Nassar, 1998). Others have found that community structure, place attachment and social trust (Brown \& Perkins, 2001; Friedrichs \& Blasius, 2003; Skogan, 1990; Taylor, 1996; Walkalate, 1998), as well as neighbourhood stability, resident appropriation, social control and a strong sense of community (Brunson, Kuo \& Sullivan, 2001; Garcia, Taylor \& Brian, 2007; Jackson, 2004; Markowitz, Bellair, Liska \& Liu, 2001; Ross, Reynolds \& Geis, 2000; Schwitzer, Woo-Kim \& Mackin, 1999) elicit feelings of well-being and safety. The prospect or legibility of a place seems to affect perceptions of safety too (Fisher \& Nassar, 1992). Familiarity and anticipated social support can also make people feel safer (Merry, 1981). Thus, instead of only focusing on physical aspects of disorder and antisocial behaviour, research investigating fear and other reactions to crime should also incorporate individual and community factors associated with place assessment such as likeability, prospect, familiarity, social control and sense of community.

The model presented at Figure 1 suggests that people assess the environment looking for signs of order and of disorder. Signs of orderliness involve not only actual but inferred attributes of places (and people) which in turn are influenced by individual and community characteristics (e.g. knowledge, beliefs, affects, culture) and past experience. We hold that when a person perceives a place as ordered then she 
or he feels safe. In contrast, if the place is perceived as disordered then a second verification is needed to estimate the risk that may be associated with the disorder.

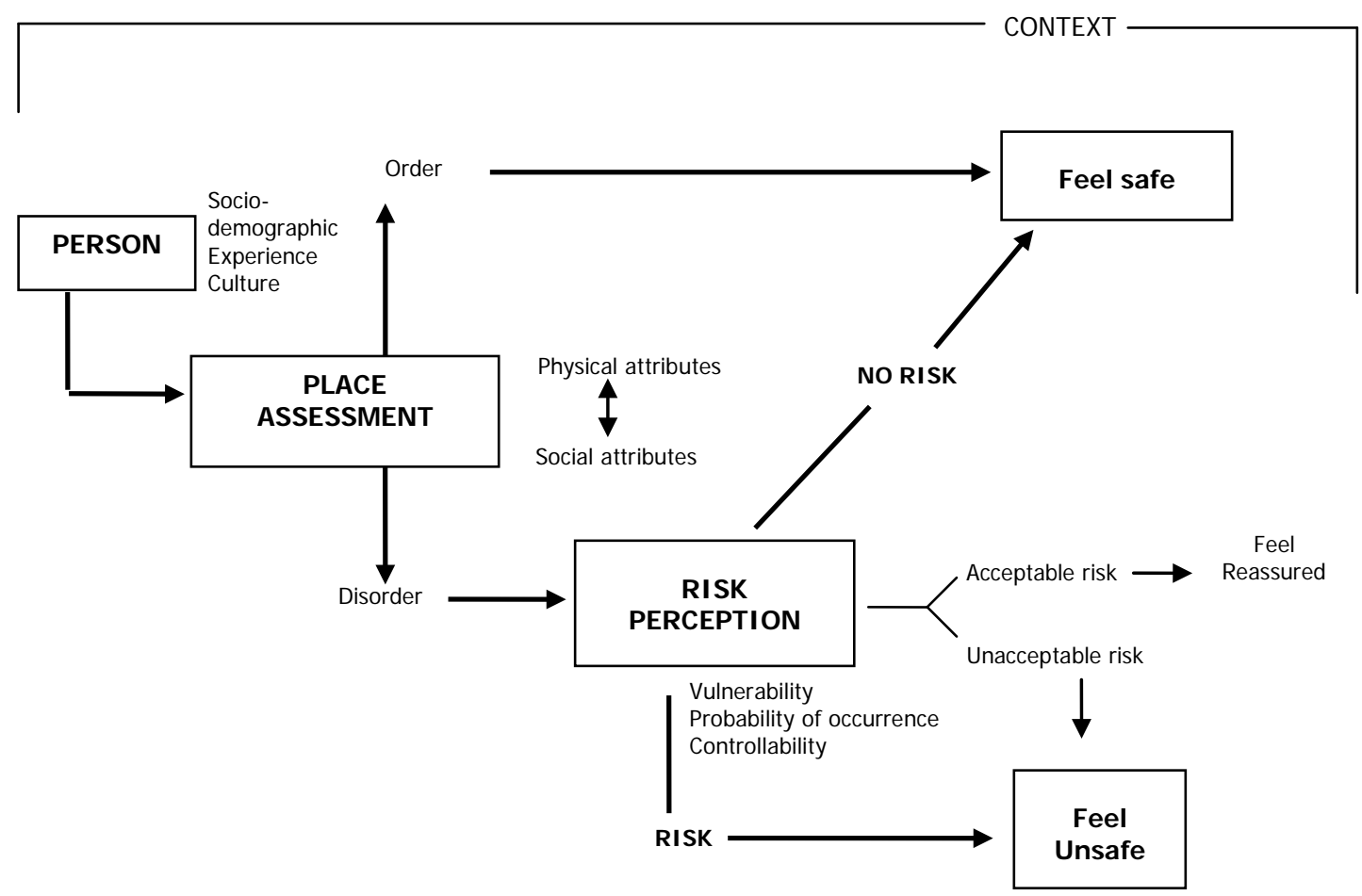

Figure 1. Model proposed to account for the relationship between perceived disorder, risk perception and perceived safety about victimisation. Because the acceptability of risks was not tested as part o the model in this study, here it has been included as a conceptual suggestion that yet needs to be examined.

If a person estimates that there is no risk, then she or he will feel safe; but if any risks have been calculated then the individual will feel unsafe. In evaluating the risk, people anticipate the danger or the benefit of the consequences that effect aspects they value (Renn, 1998), and estimate their level of vulnerability and whether they can control the risk and its possible consequences.

Literature on the fear of crime has discussed the relevance of investigating the role that vulnerability has in eliciting fear. In short, what this literature reports is that 
fear of crime depends on various factors such as socio-demographic characteristics (e.g. age, gender, poor health, poverty), perceived risk (or the likelihood of occurrence of a particular crime), the individual's sensitivity to a specific risk which in turn is influenced by the perceived seriousness of an offence and individual vulnerability (Warr, 1987); exposure to non-legible risk, anticipation of serious consequences and loss of control (Killias, 1990); the perception of oneself and the perception of the offence (Semmens, 2004). Notwithstanding the conceptual contribution that this literature has made to the field, yet risk perception and vulnerability have not been convincingly developed and little empirical evidence to support such ideas has been provided.

More recently and building upon previous approaches, other authors have developed further the notion of vulnerability. Ireland (2011), for example, conducted a study to explore conceptualizations of victimization by men, and found that threat appraisal -measured as perceived vulnerability and severity- and the effectiveness of coping strategies were significant predictors of fear of victimisation. In two other studies, Jackson (2009, 2011) examined the role that risk perception or vulnerability assessed as perceived likelihood, control and consequence- has in explaining gender and age differences in worry. He found that whilst perceived likelihood was the strongest predictor of levels of worry about crime, perceived control and perceived consequence both predicted likelihood and moderated the association between likelihood and worry. He concluded that worry about crime was a function of perceived vulnerability (or perceived risk) and that "the greater the perceived consequence and the lower the perceived control, the stronger the observed association between perceived likelihood and worry about crime (2011, p.531)”. 
Finally, Custers and Van den Bulck (2013) investigated the processes mediating the relationship between television viewing and fear of sexual violence and found that perceived risk of becoming victimized and perceived seriousness of an offense were positively related to fear. However, they did not support Jackson's findings regarding the moderating effects of perceived control and perceived seriousness on the relationship between risk perception and fear.

A major contribution of these and other studies looking into perceived vulnerability is that they shift from traditional views of disorder and incivility, to a more psychological approach where interpretive processes such as estimations of danger, probability of occurrence and likely impact, play a key role in eliciting fear or worry about crime. However, the definition of key concepts such as vulnerability and perceived risk is still ambiguous. In this paper we argue that perceived vulnerability and risk are conceptually different and that the former is in fact a key component of the perception of risk and its acceptability.

Risk implies the analysis of cause-effects relationships and the desire to reduce undesirable outcomes by accepting or rejecting the risk. It is a multidimensional and context dependant process that involves more than the judgement of the likelihood of events as traditionally investigated in the fear-risk paradox. Risk implies a subjective cognitive construction that includes social meanings and personal inferences of hazards that may impose threats to people and the things they value (Klinke \& Renn, 2002). It involves a full range of beliefs and feelings that people have about the nature of hazardous events, their qualitative characteristics and benefits, and their acceptability (Pidgeon \& Beattie, 1997:291). 
Research has shown that lay people have a broad and complex conception of risk, in which they incorporate elements such as familiarity, immediacy, knowledge about the risk, voluntariness of risk, uncertainty and dread associated to risk, as well as its controllability, frequency and severity. Many of these characteristics are correlated with each other and influence the relation between perceived risk, perceived benefit, and risk acceptance (Schütz, Holger, \& Wiedemann, 2000; Rohrmann, 1998; Slovic, 1998, 1987). Whether final estimations and judgements are actually correct is not as important to people as the potential i.e. drawing the conclusion that they can manage the event and that nothing will harm them.

Perceptions of vulnerability to encounter potentially threatening events and the controllability of risks (or the estimates of one's ability to avoid or mitigate risks and their consequences) are also said to influence the perception of risk and safety. Weinstein (1989) notes that on the one hand, those who think that are more vulnerable or susceptible of facing risks and their consequences may take costly and unnecessary protective behaviours, even when risk of victimisation is low. On the other hand, people who perceive themselves to be at lower risk of injury also believe that they are better able to control risks than other people who are exposed to same risks. Weyman and Kelly (1999) also point out that lack of self-efficacy and perceptions of uncontrollability lead people to feel more vulnerable, anxious, and unsafe. Hough (1995) found that perceived physical vulnerability significantly predicted both perceptions of safety while alone at night and worries about being mugged. 
As discussed above, estimating the likelihood of hazards' and their frequency of occurrence are also key factors to explain the perception of risk and safety. It appears that more frequent and common events are underestimated and the less frequent overestimated. Also, the less frequent an event is perceived, and the more confident people feel, the less vulnerable they think they are, and the more control over the hazard and the outcomes they think they have (Weinstein, 1989; Uzzell \& Brown, 2007). Therefore, people feel at less risk of suffering any sort of harm and, consequently, more safe.

Our model also suggests the influence of a fourth factor which may attenuate or amplify the perception of risk and safety, and that is the acceptability of the risk. Once a certain level of risk has been perceived the next step is to determine how acceptable the risk might be. If the risk is judged to be acceptable then people may feel reassured ${ }^{1}$; if not they will feel unsafe and will engage in a flight or fight response. The acceptability of the risk is based upon several features: the individual psychology of the person, the hazard, the situation, the expected consequences, and the options available (Fischhoff, Lichtenstein, Slovic, Derby \& Keeny, 1981). How voluntary and controllable the risk is, the salience of the situation, one’s personal experience, the perceived costs-benefits of each option available and the risk itself, are amongst the most important factors that affect decisions of accepting risks (Otway \& Winterfeldt, 1982). Research findings have also shown that the acceptable level of risk depends on voluntariness and perceived benefits (Barnett \& Breakwell, 2001). It seems that the more voluntary and beneficial the risk the more acceptable it is such as the choice to drive a car (Slovic, 1987; Slovic \& Weber, 2002).

\footnotetext{
${ }^{1}$ The extent a person may feel reassured as a result of accepting risks is rather a conceptual suggestion that also needs to be tested.
} 
In addition to psychosocial and contextual factors, risk assessment and risk perception are influenced by factors attributable to the risk itself. Research has demonstrated that there are a number of qualitative characteristics of the risk that can facilitate or inhibit risk perception such as familiarity, immediacy, voluntariness, probability and frequency of occurrence, duration, severity of the consequence, recurrence, controllability, population at risk, time between exposure to risk and consequences, origin (man made vs nature), level of complexity (e.g. driving vs climate change), and location (local - global) (Cutter, 1993; Hohenemser, Kates \& Slovic, 1983; Pidgeon \& Beattie, 1997; Slovic, 1987).

Many of these qualitative characteristics are correlated with each other and influence the relation between perceived risk, perceived benefit, and risk acceptance (Schütz et al, 2000; Slovic, 1992). For instance, research results have shown that people may accept risks and the possibility of being harmed if it serves other goals, but will reject even the slight chance of harm if they think the risk has been imposed on them or is contradictory to their beliefs and values (Fischhoff, 1985).

Summarising, the conceptual model described above proposes a series of relationships between psycho-social, environmental and contextual factors that allow a more coherent and conceptually rich account of perceptions of safety and potential victimisation in places. In short, the model proposes that if a place has been perceived as having with a certain level of disorder then a second appraisal of the place is done in terms of the risk it may pose to the person. We argue that perceiving disorder is not a sufficient condition to make people feel unsafe; rather, it is the perception of the risk 
which influences the perception of safety. How safe or unsafe one might feel depends on this second assessment and a person's own socio-demographic, psychological (motives, affects, experience), and socio-cultural characteristics (values, culture, social meanings).

The study presented in this paper examines the mediating role of risk perception and explores the influence that the acceptability of risks has in decision making.

\section{Method}

2.1 Sampling strategy and participant details

A sample of 120 university students was used for the analysis (Table 1). Only British participants were included in the sample because they had to evaluate British residential areas, and cultural differences were not being investigated. Using mailing lists, students from different subject areas were sent an email asking for their participation. The aim and length of the study and inclusion criteria were explained in the email. Once participants replied, a suitable day and time was arranged for them to complete the questionnaire. Posters advertising the study were also posted around the university in order to recruit more participants. 
Table 1. Demographic data.

\begin{tabular}{|c|c|c|c|}
\hline DEMOGRAPHIC & GROUPS & \multicolumn{2}{|c|}{$\%(n)$} \\
\hline \multirow{3}{*}{ Age } & $18-21$ & \multicolumn{2}{|c|}{$43.3(52)$} \\
\hline & $22-25$ & \multicolumn{2}{|c|}{$35.1(42)$} \\
\hline & $26-30$ & \multicolumn{2}{|c|}{$21.6(26)$} \\
\hline \multirow[t]{2}{*}{ Gender } & Female & \multicolumn{2}{|c|}{56.7 (68) } \\
\hline & Male & \multicolumn{2}{|c|}{$43.3(52)$} \\
\hline \multirow{5}{*}{$\begin{array}{l}\text { Area of } \\
\text { study }\end{array}$} & Psychology & \multicolumn{2}{|c|}{$34.2(41)$} \\
\hline & Engineering/Physics/Maths & \multicolumn{2}{|c|}{$26.7(32)$} \\
\hline & Biomedics & \multicolumn{2}{|c|}{$17.5(21)$} \\
\hline & Culture and Arts & \multicolumn{2}{|c|}{$10.8(13)$} \\
\hline & Other & \\
\hline Level of & Undergraduate & \multicolumn{2}{|c|}{$\begin{array}{l}61.7(74) \\
13.3(16)\end{array}$} \\
\hline studies & Masters & 13. & (16) \\
\hline & PhD & \multicolumn{2}{|c|}{$25(30)$} \\
\hline \multirow{6}{*}{$\begin{array}{l}\text { Offence } \\
\text { experience }\end{array}$} & & $\begin{array}{c}\text { Yes } \\
\%(n)\end{array}$ & $\begin{array}{c}\text { No } \\
\%(n)\end{array}$ \\
\hline & Physical/verbal attack & $47.5(57)$ & $52.5(63)$ \\
\hline & Mugged & $6.7(8)$ & $93.3(112)$ \\
\hline & Robbed & $8.3(10)$ & $91.7(110)$ \\
\hline & Burgled & $14.2(17)$ & $85.8(103)$ \\
\hline & Relatives exp victim* & $81.7(98)$ & $18.3(22)$ \\
\hline
\end{tabular}

* Participants also reported if they had heard about their relatives experiencing any of the above offences.

\subsection{Materials}

The measures and materials discussed here built upon literature reviewed and two mixed-methods studies we conducted prior to our final study (unpublished).

Materials used included three panoramic photographs of residential neighbourhoods depicting different levels of deprivation and wealth, and an open-ended questionnaire purposely devised for this study.

2.2.1 The three places with different levels of disorder

Using the English Index of Multiple Deprivation (IMD; Communities and Local Government, 2007) ${ }^{2}$ a deprived place - Petén Street ${ }^{3}$ - was identified as more

\footnotetext{
${ }^{2}$ The IMD (2007) classifies small geographical areas (lower super output areas) in England in terms of their level of deprivation.

${ }^{3}$ This is a fictitious name.
} 
convenient for this study because digital manipulations on the computer could be more easily undertaken than using a wealthier street. Petén Street is located in the second most deprived ward in the Borough and within the top $20 \%$ most deprived wards in England where crime is rather high.

A panoramic view of Petén Street as Is with no people, was taken in the daytime (Photograph 1). By manipulating its physical features, two variations of the place using a computer design programme were created: Petén Street Degraded (Photograph 2) contained more signs of incivilities and dilapidation, more cars, dirtiness, not well maintained vegetation, broken windows and graffiti; and, Petén Street Improved (Photograph 3) looked better maintained, tidier, cleaner, with fewer cars, newer windows and well-shaped greenery. The aim of such alterations was to explore how much participants’ perceptions of disorder, risk and safety, changed depending on the overall physical disorder of the same place.

The three photographs were printed in colour and were 167 cms width x 20 cms height in size. Three sets of photographs (with three photos each) were prepared as three participants completed the questionnaires at the same time. The final photographs presented to participants are shown below. 
Photograph 1. Petén Street Degraded.

The actual place was modified to create a more degraded and less attractive place were signs of decay and abandonment were evident. It included more cars and litter bins, and a police sign was drawn in the red car in front of the picture, which also had a broken window and a missing tyire. Graffiti, dirt and cracks on the walls were perceptible; broken windows and a skip were added on the right side to create a more rundown appearance. Unkempt vegetation was also included.

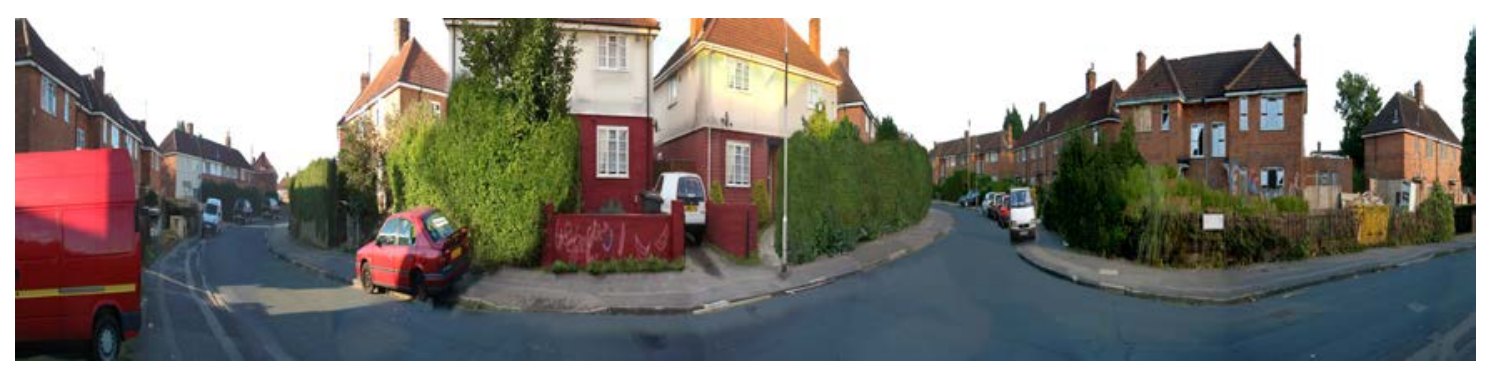

Photograph 2. Petén Street as Is. This photograph shows the place as it was in reality.

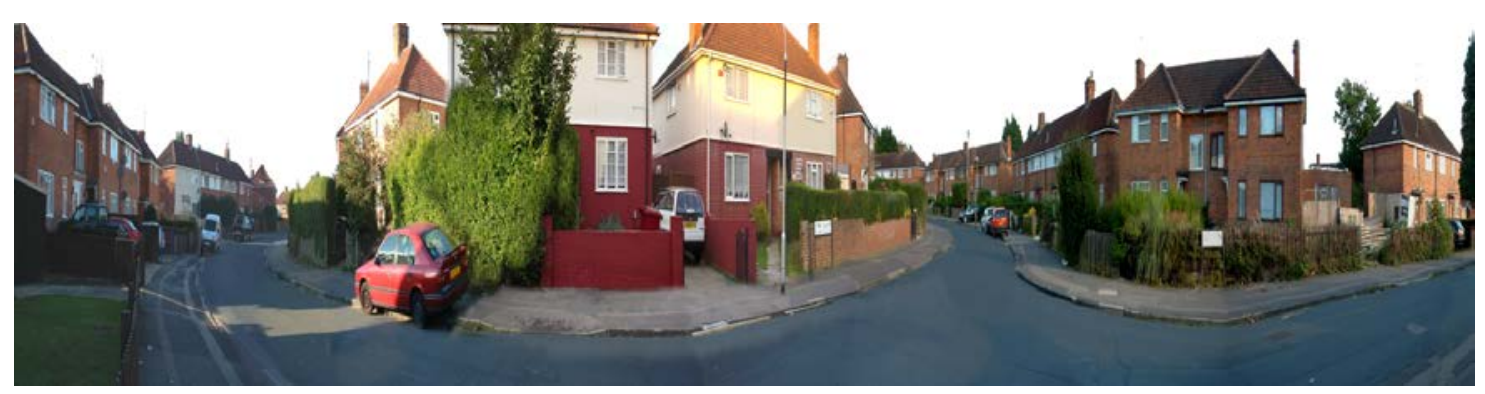

\section{Photograph 3. Petén Street Improved}

The actual place was manipulated to create a beautified and more attractive place. Most of the cars were removed from the photo, several windows were replaced by newer ones and litter and dirt were removed when possible. Well kept and shaped vegetation was added in order to create a more green, private and well cared place.

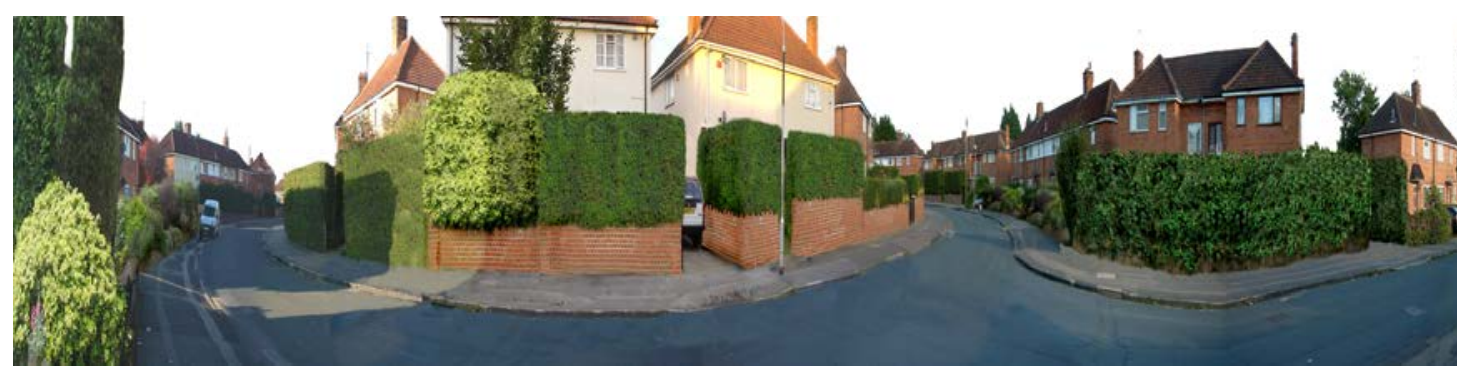




\subsubsection{The questionnaire}

A questionnaire measuring perceived disorder, risk perception and perceived safety about victimisation, was devised. Neighbourhood disorder included five subscales: physical and social incivilities, prospect, deprivation, and community involvement. Given risk perception is defined as a complex and multifactorial process, in this study it was measured with three subscales: perceived probability of occurrence of specific offences, perceived personal vulnerability and perceived control over events and their consequences. Therefore, "risk perception or perceived risk” are the terms we use to encompass these three components. A vignette measuring acceptability of risks and three additional sub-scales were included: similarity, likeability, and perceived safety. Appendix A (see end of paper) shows items and dimensions measured by the questionnaire and its associated Cronbach's alpha.

The questionnaire contained two main sections. Section I presented an openended question that explored participants' first thoughts about the place depicted in the photograph. Results from this part of the questionnaire have been presented elsewhere (Acuña-Rivera, Uzzell \& Brown, 2011) so will not be discussed in this paper. Section II of the questionnaire examined a range of dimensions relevant to neighbourhood disorder, likeability of the place and perceived similarity. Participants had to put the mark (out from 10) that best expressed their opinion, with 1 meaning “not at all”, and 10 “very much”.

Acknowledging the significant role that the acceptability of risks has in perceptions of safety, a vignette aimed to investigate when, how and why participants 
accept risks was also included. However this section was not tested as part of the model since this would incorporate additional relationships that were not investigated in this study. The hypothetical scenario made participants think about a significant event but in a probable dangerous situation in the evening. Options offered involve a benefit but also a cost. The situation and the options included were:

Please imagine you have been asked to go for dinner at a close friend's house (think of an actual very close friend of yours) because you have not seen each other for a long time and you do not know his/her new place. Your friend's house is at the end of the street in the photo. You have the address but do not know where the house is. You have also been told that the house is close to a dangerous neighbourhood. Looking at the place in the photograph and considering that you are going by yourself, please circle the option that best describes what you would actually do in these circumstances. Remember that there are no correct or wrong answers, it is your views that count.

a. Take a bus because you were told that it is very cheap and that it will leave you near your friend's house (5 minutes walk away).

b. Go by car although you cannot park in front of your friend's place because it is residential use only. However, there is a pay and display car park nearby (10 minutes walk away). about $£ 15$.

c. Take a taxi that would take you right to your friend's place and cost

d. Suggest to your friend that you have dinner somewhere else explaining that you do not know the place where she/he lives.

e. Decide to catch up on the phone instead.

Participants could accept the risk by either saving money or time although they could also reject the risk and decide not to go there and meet somewhere else or speak on the phone instead. Once participants chose an option, they were asked to briefly explain why they made that decision as a way to identify criteria used. 
Participants were asked to rate on a 7-point Likert scale with 1 denoting “never” and 7 “always”, how likely certain threats (e.g., verbal attacks, rowdy teens, mugging) would occur in the places evaluated. Participants provided their sociodemographic details in a separate slip when they had completed the questionnaires.

Literature in the field has revealed that victimisation experience influences the way people react to crime and signs associated to it although results seem contradictory (Box, Hale, \& Andrews, 1988, Brown \& Perkins, 2001; Cates, Dian \& Schnepf, 2003). In order to investigate this, participants were also asked about their experience with certain offences associated with residential areas.

\section{Procedure}

Three participants at a time completed the questionnaire in a room specifically arranged for that purpose. Each one of them had their own desk with three copies of the questionnaire, a separate slip for their general details and one of the three photographs they were going to evaluate. Although the aim of the study and instructions were explained to participants at the same time, each one of them completed the questionnaire on their own. Participants were informed that their personal data and answers would be kept anonymous and confidential and processed for research purposes only, and that they may withdraw from the study should they want to. In addition, full results were also available for those interested.

Participants also had in front of them the photograph they were evaluating and were allowed to see it as many times as needed. Once they completed the questionnaire for the first photograph, the researcher collected it and gave them the 
second photo and then the third one. They completed one questionnaire for each photo. The length of the session ranged from 45 minutes to one hour. Although participants evaluated the three photographs, its order of presentation was counterbalanced in order to avoid always having the same photo evaluated in first, second or third place. This procedure is explained in the next section.

\section{Results}

\subsection{Dimension construction}

Because of their low correlation with other items $(r<.30)$, four items were deleted from the questionnaire. The internal consistency of all subscales and for the three places evaluated was good (Cronbach’s alpha $>.70 ; \mathrm{p}<.05$ ), except for prospect which was rather moderate (Cronbach's alpha $=.60 ; \mathrm{p}<.05)$. The three items related to perceived controllability were included in the analysis separately, as the internal consistency of the subscale was poor (Cronbach’s alpha <.50; $<<.05$ ).

4.2 Three places with different levels of disorder, risk and safety

Before exploring the role that the dimensions measured has in perceived risk and safety, it was necessary to determine whether the modifications made to the real place worked in terms of creating three places with different levels of disorder, risk and safety. A series of one-way repeated measures ANOVAs were performed to identify significant differences in participants’ perceptions of the three places evaluated. Pairwise comparisons using Games-Howell Post hoc tests were performed in order to determine where the significant differences occurred (Field, 2009). Bonferroni correction was also applied to the $\mathrm{p}<.05$ since multiple significance tests were carried out. 
Results showed that the three places created were perceived with significantly different levels of disorder, safety and risk $(\mathrm{p}<.001)$ where Petén Street Degraded always received the least favourable evaluation and Petén Street Improved the best. Even though Petén Street as Is was perceived as physically disordered and somewhat deprived, it was not considered as socially disordered or unsafe as the degraded place (Table 2).

Table 2. Means and standard deviations for each place and for each dimension measured (significant differences between the three places were found at $p<.001$ )

\begin{tabular}{|c|c|c|c|c|}
\hline DIMENSION & $\begin{array}{c}\text { DEGRADED } \\
\mathrm{m}(\mathrm{std})\end{array}$ & $\begin{array}{c}\text { as IS } \\
\text { m (std) }\end{array}$ & $\begin{array}{l}\text { IMPROVED } \\
\text { m(std) }\end{array}$ & Response scale \\
\hline Physical Order & $4.0(1.2)$ & $5.8(1.4)$ & $7.6(1.1)$ & $\begin{array}{l}1=\text { Not at all } \\
10=\text { Very much }\end{array}$ \\
\hline Social Order & $3.9(1.1)$ & $5.8(1.4)$ & $7.1(1.2)$ & \\
\hline Similar to me & $3.1(1.0)$ & $4.9(1.4)$ & $6.2(1.3)$ & \\
\hline Like it & $2.1(0.8)$ & $4.7(1.7)$ & $6.7(1.6)$ & \\
\hline $\begin{array}{l}\text { Probability of } \\
\text { occurrence }\end{array}$ & $5.0(0.6)$ & $3.5(0.9)$ & $2.5(0.7)$ & $\begin{array}{l}\text { 1= Never } \\
\text { 7= Always }\end{array}$ \\
\hline Not vulnerable* & $3.5(1.0)$ & $4.7(0.9)$ & $5.2(0.9)$ & \\
\hline $\begin{array}{l}\text { Able to handle } \\
\text { problems* }\end{array}$ & $3.6(1.4)$ & $4.5(1.3)$ & $4.8(1.4)$ & \\
\hline Safety & $2.7(0.9)$ & $4.5(1.0)$ & $5.4(0.9)$ & \\
\hline
\end{tabular}

* Items were reversed for comparison purposes

It is worth mentioning that no significant differences by gender, age and victimisation experience were found.

\subsection{Exploring the acceptability of risks}

Acceptability of the risk is one of the key elements influencing risk perception and safety. It was measured through a vignette that was presented to participants in order to evaluate their acceptance of a likely dangerous situation for each of the places assessed (see section 2.2.2). After reading the fragment, participants were asked to 
rate how significant meeting their friend and getting to their place was for them.

Findings showed that despite meeting their friend is important to participants irrespectively of the place $(\mathrm{F}(2,207)=6.465 ; \mathrm{p}<.01)$, getting to their friend's house is more important in Petén Street as Is and Petén Street Improved, than in Petén Street Degraded $(\mathrm{F}(2,207)=6.465 ; \mathrm{p}<.01)$.

Results also showed a significant association between the type of place and the option chosen to get there $\left(X^{2}(6)=54.07, \mathrm{p}<.001\right)$. It seems that "going by bus and walking for 5 minutes”, was the most preferred option, although there were more people willing to do that in Petén Street as Is (63\%) and Petén Street Improved (61\%), than in Petén Street Degraded (41\%). See Table 3.

Table 3. Option chosen by participants to get to their friend's new place.

\begin{tabular}{|l|ccc|ccc|ccc|}
\hline \multicolumn{1}{|c|}{ Place } & \multicolumn{3}{|c|}{ Degraded* $^{*}$} & \multicolumn{3}{c|}{ as It Is* $^{*}$} & \multicolumn{3}{c|}{ Improved } \\
\hline Option & $\mathrm{T} \%(\mathrm{n})$ & $\mathrm{Fem}$ & Male & $\mathrm{T} \%(\mathrm{n})$ & $\mathrm{Fem}$ & Male & $\mathrm{T} \%(\mathrm{n})$ & Fem & Male \\
\hline By bus and 5 min walk & $41(49)$ & 26 & 23 & $63(75)$ & 41 & 34 & $61(73)$ & 40 & 33 \\
$\begin{array}{l}\text { By own car and 10 min } \\
\text { walk }\end{array}$ & $10(12)$ & 3 & 9 & $21(25)$ & 9 & 16 & $28(34)$ & 17 & 17 \\
By taxi (£15) & $26(31)$ & 18 & 13 & $9(11)$ & 9 & 2 & $4(5)$ & 3 & 2 \\
$\begin{array}{l}\text { Have dinner somewhere } \\
\text { else }\end{array}$ & $22(26)$ & 19 & 7 & $7(9)$ & 9 & --- & $7(8)$ & 8 & -- \\
Catch up on the phone & $2(2)$ & 2 & --- & --- & --- & --- & -- & --- & -- \\
\multicolumn{1}{|c|}{ Total } & 120 & 68 & 52 & 120 & 68 & 52 & 120 & 68 & 52 \\
\hline
\end{tabular}

* Significant differences by gender were found in Petén Street Degraded and Petén Street as Is at p<.05.

Broadly speaking, around $70 \%$ of the participants in the degraded place and $90 \%$ in the other two places accepted the risk of visiting their friend, although the preferred option to get there was dependant on the type of place and whether they were women or men. Interestingly, about $25 \%$ of the sample did not accept the risk and reported that having dinner somewhere else or even speaking on the phone with 
their friend was best for them, especially in the degraded place (against 7\% of participants who chose these options in the other two places).

The reasons given by $50 \%$ of the sample to explain why they chose a specific option were content analysed, and results showed that participants took into consideration three main reasons to accept the risk: time to get to their friend's place (short time walk), cost (cheapest option), and level of perceived safety in the place.

In addition, a significant association between option chosen and gender was found in the degraded $\left(X^{2}(4)=9.565, \mathrm{p}<.05\right)$ and the actual places $\left(X^{2}(3)=14.187\right.$, $\mathrm{p}<.01$. That is, women were more likely than men, to go by bus or by taxi, or even would have dinner somewhere else; whereas men were more likely to go by car. No significant association between option chosen and gender was found for the improved place.

4.4 Testing the mediating role of risk perception

To test for the potential mediating role of risk perception, steps suggested by Baron and Keney (1986) and Sobel and Aroian (Fife-Shaw, 2007) were followed. A series of standard multiple regression analyses were performed to test that:

1) perceived (dis)order (X) significantly predicts risk perception (M);

2) perceived (dis)order significantly predicts perceived safety (Y); and, 3) perceived risk significantly predicts perceived safety after controlling for perceived (dis)order. A significant reduction of the effect of (dis)order on safety when introducing risk perception, is expected (See Figure 2). 


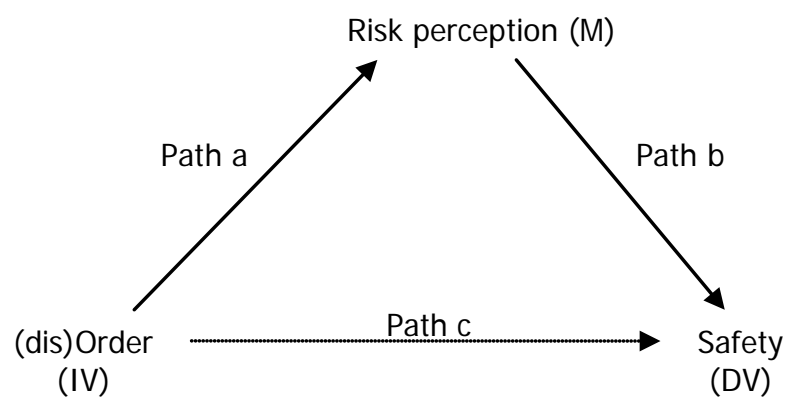

Note: Risk perception is measured by means of perceived vulnerability, frequency of occurrence and the ability to handle problems.

It is acknowledged that full mediation (when path $c$ is reduced to zero) is rare in psychological research, as most psychological processes have multiple mediating factors. Therefore, it is more realistic to look for mediators that significantly decrease path $c$, that is, partial mediation. This will demonstrate that indeed the mediator is powerful (Baron \& Kenney, 1986; Preacher \& Hayes, 2004).

Once the conditions depicted in Figure 2 are met, it is also necessary to look at whether the indirect effect of the IV on the DV (via the mediator (M) is significantly different from zero $(\mathrm{p}<.05)$, which is what the Sobel and Aroian test does. Regression coefficients for paths a and b (Figure 2) and their standard error were inputted into the Sobel and Aroian Test Calculator (Fife-Schaw, 2007). The resulting Z scores must be \pm 1.96 to be significant at $\mathrm{p}<.05$. If significant, the mediation has been achieved.

It was decided that for testing the mediating role of risk perception, physical and social disorder should be entered as one variable. A new variable called 
“disorder” was computed for each place evaluated, and it included all items from physical and social disorder and community involvement as the latter has been found to be a key variable in people's perceptions of neighbourhood disorder (Skogan, 1990; Fisher, Sonn, \& Bishop, 2002). Internal consistency of the three new variables (one for each place assessed) was tested using Cronbach's alpha $(\mathrm{p}<0.05)$, and reliability coefficients proved to be satisfactory for all of them (Cronbach's alpha=.78 in the degraded place; Cronbach's alpha=.83 in the place as Is; and, Cronbach's alpha=.82 in the improved place).

Perceived vulnerability, probability and ability to handle problems, were included in the analysis as three different variables, in order to explore the role that each one of them have in the disorder-safety relationship. The other items from the controllability dimension were not considered in the analysis as they did not predict safety. Findings for each place will be analysed first, including results from both the multiple regressions and the Sobel and Aroian tests, and then a concluding summary will be presented.

\subsubsection{Petén Street Degraded}

Results from Table 4 show that the three conditions to test for mediation in the degraded place were met (Table 4 can be found at the end of this paper). First, perceived disorder significantly predicted safety (Adjusted $\mathrm{R}^{2}=.354 ; \mathrm{F}(1,98)=55.270$; $\mathrm{p}=.000$ ), vulnerability (Adjusted $\mathrm{R}^{2}=.306 ; \mathrm{F}(1,102)=46.486 ; \mathrm{p}=.000$ ), probability of occurrence (Adjusted $\mathrm{R}^{2}=.397 ; \mathrm{F}(1,96)=64.945 ; \mathrm{p}=.000$ ), and the ability to handle problems (Adjusted $\mathrm{R}^{2}=.056 ; \mathrm{F}(1,104)=7.186 ; \mathrm{p}=.00$ ). Nonetheless, it is worth noting that the adjusted regression coefficient for the ability to handle problems despite 
significant was rather low as only five percent of the variation in this ability was explained by perceived disorder.

Second, vulnerability (Adjusted $\mathrm{R}^{2}=.484 ; \mathrm{F}(1,108)=103.335 ; \mathrm{p}=.000$ ), probability of occurrence (Adjusted $\mathrm{R}^{2}=.338 ; \mathrm{F}(1,101)=53.147 ; \mathrm{p}=.000$ ) and the ability to handle problems (Adjusted $\mathrm{R}^{2}=.111 ; \mathrm{F}(1,110)=14.867 ; \mathrm{p}=.000$ ) all three significantly accounted for perceived safety.

Third, perceived vulnerability, probability and handle problems together significantly accounted for $60 \%$ of the variation in perceived safety (Adjusted $\left.\mathrm{R}^{2}=.593 ; \mathrm{F}(4,93)=36.309 ; \mathrm{p}=.000\right)$, being vulnerability the strongest predictor. Interestingly, the effect of perceived disorder is no longer significant when the mediators were included, although it was not equal to zero. By looking at the regression coefficients (B) and the semi-partial correlations (part) for perceived disorder (Table 4), it can be observed that the effect from disorder on safety is reduced when the mediators are included. That is, B decreases from .609 to .149, and the semi-partial correlations from .601 to .104. Therefore, a partial mediation of vulnerability, probability and the ability to handle problems, was found.

Regression coefficients for paths a and b and their standard errors were inputted into the Sobel and Aroian Test Calculator and results confirmed that risk perception by means of their indicators partially mediates the relationship between disorder and safety in Petén Street Degraded (Table 5). 
Table 5. Sobel and Aroian z scores for testing the mediating role of risk perception in the three places evaluated.

\begin{tabular}{lll}
\hline Petén Street Degraded & & \\
\hline \multicolumn{1}{c}{ Variable } & Sobel & Aroian \\
\hline Vulnerability & 4.12 & 4.10 \\
Probability & -2.53 & -2.50 \\
Handle problems & 2.79 & 2.78 \\
& & \\
\hline Petén Street as Is & & \\
\hline Disorder & 2.77 & 2.75 \\
Vulnerability & 3.04 & 3.02 \\
Probability & -2.27 & -2.25 \\
Handle problems & 2.26 & 2.25 \\
& & \\
\hline Petén Street Improved & & \\
\hline Disorder & 2.30 & 2.28 \\
Vulnerability & 3.91 & 3.88 \\
& & \\
\hline$Z$
\end{tabular}

$Z$ score $> \pm 1.96$ to be significant at $p>.05$

\subsubsection{Petén Street as Is}

Results from Table 6 show that the three conditions to test for mediation in the actual place were met too (Table 6 can be found at the end of this paper). First, perceived disorder significantly predicted safety (Adjusted $\mathrm{R}^{2}=.479 ; \mathrm{F}(1,98)=92.035$; $\mathrm{p}=.000$ ), vulnerability (Adjusted $\mathrm{R}^{2}=.383 ; \mathrm{F}(1,102)=64.974 ; \mathrm{p}=.000$ ), probability of occurrence (Adjusted $\mathrm{R}^{2}=.463 ; \mathrm{F}(1,96)=84.738 ; \mathrm{p}=.000$ ), and the ability to handle problems (Adjusted $\mathrm{R}^{2}=.091 ; \mathrm{F}(1,96)=11.495 ; \mathrm{p}=.001$ ). Once again, perceived disorder significantly accounts for only nine percent of the variation in the ability to handle problems. Second, perceived vulnerability, probability and handle problems significantly account for perceived safety (Adjusted $\mathrm{R}^{2}=.420 ; \mathrm{F}(1,108)=79.807$, $\mathrm{p}=.000 ;$ Adjusted $\mathrm{R}^{2}=.312 ; \mathrm{F}(1,101)=47.262, \mathrm{p}=.000$; and, Adjusted $\mathrm{R}^{2}=.182$; $F(1,10)=25.711 ; p=.000$, respectively). Third, all variables together predicted around 
$59 \%$ of the variation in perceived safety, being vulnerability the strongest predictor (Adjusted $\mathrm{R}^{2}=.587 ; \mathrm{F}(4,93)=35.534, \mathrm{p}=.000$ ). In this case, the effect of perceived disorder on perceived safety was significant.

By looking at the regression coefficients (B) and the semi-partial correlations (part) for perceived disorder, it can be observed that the effect from disorder on safety was reduced when the mediators were included. That is, B decreased from .651 to .292, and the semi-partial correlations from .696 to .192. Therefore, a partial mediation of vulnerability, probability and the ability to handle problems was again found. Regression coefficients and their standard errors were inputted into the Sobel and Aroian Test Calculator and results showed that the absolute values for perceived disorder, vulnerability, danger and the ability to handle problems, are significant. This result confirmed that risk perception partially mediated the relationship between disorder and safety in Petén Street as Is (Table 5).

\subsubsection{Petén Street Improved}

Results from Table 7 (this table can be found at the end of this paper) demonstrate that perceived order significantly predicted safety (Adjusted $\mathrm{R}^{2}=.325$; $\mathrm{F}(1,98)=48.661 ; \mathrm{p}=.000)$, vulnerability (Adjusted $\mathrm{R}^{2}=.285 ; \mathrm{F}(1,102)=42.048 ; \mathrm{p}=.000$ ), probability of occurrence (Adjusted $\mathrm{R}^{2}=.486 ; \mathrm{F}(1,96)=92.628 ; \mathrm{p}=.000$ ), and the ability to handle problems (Adjusted $\mathrm{R}^{2}=.052 ; \mathrm{F}(1,104)=6.815 ; \mathrm{p}=.010$ ); and that vulnerability, danger and handle problems also predicted safety (Adjusted $\mathrm{R}^{2}=.436$; $\mathrm{F}(1,108)=85.332, \mathrm{p}=.000$; Adjusted $\mathrm{R}^{2}=.238 ; \mathrm{F}(1,101)=32.909, \mathrm{p}=.000$; and, Adjusted $\mathrm{R}^{2}=.086 ; \mathrm{F}(1,110)=11.476 ; \mathrm{p}=.001$ respectively). Nevertheless, only perceived order and vulnerability significantly accounted for $50 \%$ of the variation in perceived safety 
(Adjusted $\mathrm{R}^{2}=.492 ; \mathrm{F}(4,93)=24.449, \mathrm{p}=.000$ ), as probability of occurrence and handle problems were no longer significant.

By looking at the regression coefficients (B) and the semi-partial correlations for perceived disorder, it can be said that the effect of order on safety was decreased when the mediators were included. That is, B decreased from .518 to .239, and the semi-partial correlations from .576 to .178 . Therefore, a partial mediation of vulnerability was achieved.

Regression coefficients and their standard errors were inputted into the Sobel and Aroian Test Calculator and results show that indeed absolute values for perceived disorder and vulnerability were significant. This result confirms that vulnerability partially mediates the relationship between order and safety in Petén Street Improved (Table 5).

To summarise, the results confirm that risk perception partially mediates the relationship between perceived disorder and safety since the effect of disorder on safety became small when the variables associated with perceived risk were included, especially in the degraded place where it was no longer significant. In all places evaluated, perceived vulnerability was the strongest predictor and mediator. This suggests that when a place has been perceived with a certain level of physical and social disorder then risk perception helps people to determine how safe or unsafe they might be. 


\section{Discussion}

Given the limitations of current formulations to define adequately a conceptual framework to account for perceptual and interpretive processes that occur when people assess their safety in places, this paper introduces a new conceptual approach to the investigation of risk perception and its effect on perceived safety about crime. Our model proposes that evaluating the level of safety involves two types of assessments, one to determine the level of physical and social disorder and a second to estimate the possibility of facing risks and their consequences.

To test our assumption, three places with different levels of physical and social disorder were created. Results showed that modifications performed to the real place in order to create two versions of the place with discernibly different levels of deprivation, worked. The degraded place was perceived as the most unsafe and risky, and was at the same time the most physically and socially disordered neighbourhood. The other two places were evaluated as socially ordered, rather safe and with low risk, even when the actual place was perceived as physically disordered and somewhat deprived. However, the improved place always received the most favourable assessment. It seems to be that the level of perceived social disorder made the difference between the unsafe and safe places. What this is telling us is that it is not the physical environment per se but the psychosocial attributions and inferences about people and places which inform us about how safe we might be; it is inferences about people and their behaviour that matter the most.

When testing the model, findings demonstrated that indeed risk perception partially mediated the relationship between perceived disorder and safety, since the effect of the former on the latter became small when the three components of risk 
perception were included, especially in the degraded place where it was no longer significant. That is, the more disordered a place is perceived the more a person relies on the perception of risk to estimate how safe she or he might be in it. People not only rely upon observed or inferred attributes of places and hazards to estimate the level of safety but on other more individual factors such as the likelihood of occurrence of certain offences, how vulnerable to suffering any type of harm one might be, and how controllable hazards and consequences are. In all cases, perceived vulnerability (or the subjective evaluation of an individual's susceptibility when facing threatening events that may harm them or the things they value) was the strongest predictor and mediator. These findings represent an important conceptual and empirical contribution to the field.

Even though our findings seem to go in a similar direction to recent studies investigating vulnerability and/or risk perception and their effect on fear or worry about crime, key differences are identified. For instance, in some of these studies, perceived vulnerability and risk perception are used as synonyms and are defined as the perceived likelihood of victimisation, personal control over the threat and anticipated consequences (Custers \& Van den Bulck, 2013; Jackson, 2009, 2011). In this paper, a clear distinction between perceived vulnerability and perceived risk has been made, situating vulnerability as a necessary condition for risk perception. From this point o view, risk perception is a multidimensional and context dependant concept which is defined as the way people judge and evaluate the hazards they are or might be exposed to and it includes beliefs, attitudes, judgements and feelings, as well as the wider cultural and social dispositions people adopt towards threats to themselves or the things they value (Pidgeon, 1998: 5). Vulnerability, on the other 
hand, is defined as people's perceived susceptibility of encountering threatening events or situations that may harm them or the things they value (Weyman \& Kelly, 1999). Overall, it seems that perceived vulnerability is a good predictor of fear or perceived safety about crime.

Another key difference with previous studies is that we considered a less investigated factor that may amplify or attenuate people’s perception of risk and safety: the acceptability of risk. Although this was not specifically tested as part of the model, responses to this part of the study yielded significant findings. The perceived levels of disorder, risk and (un)safety did not affect the participants’ main goal (visiting their friend) but the way to get there. It seems that despite recognising the risk(s) associated with the place and event, participants accepted the likely risk and found ways of dealing with it. That is, the acceptability of the risk triggered precautionary behaviours (Van der Plight, 1998) that, according to the participants, helped them to attain their goal and face the likely risk. Participants weighted the situation in terms of time spent and cost of each option provided, and even reconsidered the "safeness" of the place. Option chosen was the most convenient for them either because they saved money or time, or because they thought neither themselves nor their cars were at risk. It seems that participants adjusted their preexisting conceptions towards their personal risk and safety and accepted the risk because achieving their goal was more important. The salience and the goal of the situation, the affects involved, the perceived costs and benefits, and the voluntariness of the risk influenced their decision making and future behaviour. This is consistent with other research findings (Otway \& Winterfeldt, 1982; Slovic, Finucane, Peters \& McGregor, 2004). 
Most research in the field of risk perception has demonstrated that risks that are voluntary undertaken are more likely to be accepted; our results confirmed this. Fischhoff (1985) argues that people may accept risks and the possibility of being harmed if it serves other significant goals, but will reject any possibility of harm if they think the risk has been imposed on them or is contradictory to their beliefs and values. Thus, research investigating the fear of crime and why some groups seem to be more fearful than others should also incorporate attitudes, beliefs and values towards specific offences (and not crime in general) and whether these are perceived as imposed risks that should be controlled by somebody else. Identifying which offences are more accepted (or tolerated) than others and under what circumstances would be significant too.

Another key finding is that regarding the effect that socio-demographic characteristics have in perceived disorder, risk and safety. Surprisingly, no significant differences by gender, age and victimisation experience were found in terms of perceptions of disorder, risk and safety which contradicts previous research (Brantingham \& Brantingham, 1995; Franzini et al, 2008; Friederichs \& Blasius, 2003; Kuo \& Sullivan, 2001; Miceli, Rocato \& Rosato, 2004; Wilson \& Kelling, 1982). However, significant differences regarding the acceptability of risks were found. The majority of the participants accepted the risk anticipated in each neighbourhood although the preferred option to get to each place was dependant on the type of area and whether they were women or men. This again could be related with the salience of the situation, its affective connotation, and the perceived benefits and costs. 
It seems plausible to conclude that estimating personal safety implies more than assessing how physically and socially disordered a place is. Modifying the physical environment is not sufficient to reduce fear and unsafe feelings, rather understanding how people perceive and accept risks will prove more effective to explain perceptions of safety about victimisation. Notwithstanding the conceptual and empirical formulations presented in this paper represent a theoretical improvement, a number of questions yet remain unanswered.

More research refining the relationships suggested and testing competing models would be significant. It would also be important to investigate further other determinants of risk and its acceptability such as perceived seriousness of the risk and its consequences, immediacy of the consequences, familiarity, affect, social structure and trust. Future work should be more process oriented and needs to investigate how perceptions and interpretations of the environment and safety are construed and adjusted according to personal, social and contextual factors. It will be important to incorporate other psychosocial variables that have proved relevant to explain residential satisfaction and sense of community, such as place attachment, social cohesion, identity and trust. Incorporating people’s understandings and conceptualisations of victimisation and considering contextualists formulations to investigate the role that social and institutional processes have in amplifying or attenuating public’s views is also needed (Innes \& Jones, 2006; Thompson \& Dean, 1996).

Investigating more effectively the impact that emotional and affective reactions have in people's responses to crime is crucial too. Slovic and Peters (2006) 
support the idea that retrieving affective impressions serve as an early warning system that involves an intuitive, fast, and mostly automatic reaction to danger. It would be important to investigate under what circumstances people rely on either affective reactions or rational thinking, or whether a person's response rather reflects the action of both systems running in parallel (Slovic et al, 2004) and interacting with each other at some point in the process. In addition, investigating the type of feelings that are triggered or associated with specific offences and situations and how this affects people's perception of risk and benefit may yield interesting results. Finucane, Alhakami, Slovic, and Johnson (2000) argue that people judge risks not only by what they think but also by how they feel about it. If their feelings toward an event or situation are favourable then the perceived risk will be low and the benefit high; if their feelings are unfavourable then people will perceive high risk and low benefit.

Researchers have relied much on the "availability heuristic" (Tversky \& Kahneman, 1974, 1982) or the participant's cognitive ability to recall and imagine events, and have focused more on the anticipation of fear which is qualitatively different from experiencing actual fear (Garofalo, 1981). From a psychological point of view, fear is an emotional reaction to events appraised as threatening and it results from the interaction between biological, psycho-social and environmental factors occurring under specific circumstances (Power \& Dalgleish, 1997).

Further, the same event may produce anger in one person (which may attenuate risk) and fear in another (which may amplify risk), or even no emotional reaction at all; it will depend on the individual, the circumstances and cognitions surrounding the event (Christianson, 1992). Incorporating the influence of affective reactions and its interaction with cognitive interpretations of events yet represents a 
significant challenge not only for research on fear of crime, but for risk perception research.

As has been largely discussed, some priority should also be given to conducting multidisciplinary research to achieve conceptual and operational consensus and clarity in the definition of key terms such as disorder, worry, concern, fear, vulnerability, risk and safety. Even though there is a certain agreement on the physical and social attributes that constitute what has been called disorder and incivilities, it is yet necessary to investigate how many and which incivilities are more associated with unsafe feelings and fear. It is also necessary to investigate the differential effect that the interaction between incivilities has in perceptions of places. Improving and standardising, to a certain extent, the concepts and methodologies used would be important if more conclusive and consistent findings are to be achieved.

Finally, findings from this study demonstrated that the relationship between disorder, risk and safety is not as simple as one can expect and that it is time for scientists, designers and policy makers to move away from narrow and deterministic views. How safe is safe enough is difficult to explain since this involves factors related to the individual, the hazard, the consequences, and the context. Thus, identifying acceptable or standard levels of order and risk to create safer environments depends on to whom it might be acceptable, when, and under what circumstances (Pidgeon, Hood, Jones, Turner, \& Gibson, 1992: 92). Investigating all these factors will prove beneficial to understand at least in part why some communities seem to be more disorder and risk tolerant and why particular people feel more unsafe than others. 


\section{References}

Acuña-Rivera M, Uzzell D, Brown J (2011). Perceptions of disorder, risk and safety: The method and framing effects. Psyecology: Revista Bilingüe de Psicología Ambiental - Bilingual Journal of Environmental Psychology, 2(2):167-177

Alkahami, A. S. \& Slovic, P. (1994). A psychological study of the inverse relationship between perceived risk and perceived benefit. Risk Analysis, 14(6), 1085-1096.

Baron, R. M. \& Keney, D. A. (1986). The moderator-mediator variable distinction in social psychological research: Conceptual, strategic, and statistical considerations. Journal of Personality and Social Psychology, 51, 1173-1182.

Barnett, J. \& Breakwell, G. M. (2001). Risk perception and experience: Hazard personality profiles and individual differences. Risk Analysis, 21 (1), 171-177.

Box, S., Hale, C. \& Andrews, G. (1988). Explaining fear of crime. British Journal of Criminology, 28(3), 340-356.

Brantingham, P. \& Brantingham, P. (1995). Criminality of place. Crime generators and crime attractors. European Journal on Criminal Policy and research, 3, 526.

Brown, B. B. Perkins, D. D., \& Brown, G. (2004). Incivilities, place attachment and crime: Block and individual effects. Journal of Environmental Psychology, 24, 359-371.

Brown, B. B. \& Perkins, D.D. (2001). Neighbourhood revitalization and disorder: An intervention evaluation. Executive summary of final report to the National Institute of Justice. Salt Lake City: University of Utah. Retrieved from: https://www.ncjrs.gov/App/Publications/abstract.aspx?ID=196669 
Brunson, L., Kuo, F. E. \& Sullivan, W. C. (2001). Resident appropriation of defensible space in public housing: Implications for Safety and Community. Environment and Behavior, 33(5), 626-652.

Brunton-Smith, I., \& Sturgis, P. (2011) 'Do Neighborhoods Generate Fear of Crime?: An Empirical Test Using the British Crime Survey’. Criminology, 49(2): 331369.

Cates, J. A., Dian, D. A. \& Schnepf, G. W. (2003). Use of motivation protection theory to assess fear of crime in rural areas. Psychology, Crime and Law. 9(3), 225-236.

Chadee, D., Austen, L. \& Ditton, J. (2007). The relationship between likelihood and fear of criminal victimization. British Journal of Criminology. 47, 133-153.

Communities and Local Government (2007). The English Indices of Deprivation 2007. UK: Communities and Local Government Publications.

Cozens, P., Hillier, D. \& Prescott, G. (2001). Crime and the design of residential property: Exploring the theoretical background (Part 2). Property management, 19(2), 136-164.

Custers, K. \& Van den Bulck, J. (2013). The cultivation of fear of sexual violence in women: Processess and moderators of the relationship between television and fear. Communication Research, 40 (1), 96-124.

Cutter, S. L. (1993). Living with risk. Great Britain: Routledge. 207 pp.

Doran, B. J. \& Lees, B. G. (2005). Investigating the spatiotemporal links between disorder, crime, and the fear of crime. The Professional Geographer, 57(1), 112. 
Farrall, S., Gray, E. \& Jackson, J. (2007). Theorising the fear of crime: The cultural and social significance of insecurities about crime. Retrieved from: http://papers.ssrn.com/sol3/papers.cfm?abstract_id=1012393

Ferraro, K. F. (1995). Fear of crime: Interpreting victimization risk. New York: State University of New York.

Field, A. (2009). Discovering statistics using SPSS. 821pp, $3^{\text {rd }}$ edition. UK: Sage Publications.

Fife-Schaw, C. (2007). How can I tell whether a variable mediates the relationship between two other variables? Retrieved from http://www.surrey.ac.uk/psychology/current/statistics/index.htm

Finucane, M.L., Alhakami, A., Slovic, P., \& Johnson, S.M. (2000). The affect heuristic in judgments of risks and benefits. Journal of Behavioral Decision Making, 13, 1-17.

Fischhoff, B. (1985). Managing risk perceptions. Issues in Science and Technology. 2 (1), 83-96.

Fischhoff, B., Lichtenstein, S., Slovic, P., Derby, S. \& Keeny, R. (1981). Acceptable Risk. New York: Cambridge University Press.

Fisher, A.T., Sonn, C.C., \& Bishop, B.J. (2002). Psychological sense of community: Research, applications and implications. Kluwer Academic/Plenum.

Fisher, B. S. \& Nassar J. L. (1992). Fear of crime in relation to three exterior site features: Prospect, refuge and escape. Environment and Behavior 24, 35-65.

Franzini, L., O’Brien, M., Murray, S. \& O’Campo, P. (2008). Perceptions of disorder: Contributions of neighbourhood characteristics to subjective perceptions of disorder. Journal of Environmental Psychology, 28, 83-93. 
Friederichs, J., \& Blasius, J. (2003). Social norms in distressed neighbourhoods: Testing the Wilson hypothesis. Housing Studies, 18 (6), 807-826.

Gabriel, U., \& Greeve, W. (2003). The psychology of fear of crime: Conceptual and methodological perspectives. British Journal of Criminology, 43, 600-614.

Garcia, R. M., Taylor, R. B. \& Brian, A. L. (2007). Impacts of violent crime and neighbourhood structure on trusting your neighbours. Justice Quarterly, 24 (4), 679-704.

Garofalo, J. (1981). The fear of crime: Causes and consequences. The Journal of Criminal Law and Criminology, 72(2), 839-857

Hale, C. (1996). Fear of Crime: A review of the literature. International Review of Victimology, 4, 79-150.

Hohenemser, C., Kates, R. W. \& Slovic, P. (1983). A causal taxonomy. In: R. W. Kates, C. Hohenemser, and Kasperson, R. E. (Eds.): Perilous progress: Managing the hazards of technology (pp. 67-90). Boulder: Westview Press. Hough, M. (1995). Anxiety about crime: Findings from the 1994 British Crime Survey. Home Office Research Study No. 147. London: Home Office. Hunter, A. (1978). Symbols of incivility: Social disorder and fear of crime in urban neighbourhoods. Department of Justice. US. Paper presented at the 1978 meeting of the American Society of Criminology, Dallas, Texas.

Innes, M., \& Jones, V. (2006). Neighbourhood security and urban change: Risk, resilience and recovery. UK: Joseph Rountree Foundation. 66pp.

Jackson, J. (2011). Revisiting risk sensitivity in the fear of crime. Journal of Research in Crime and Delinquency, 48(4), 513-537.

Jackson, J. (2009). A psychological perspective on vulnerability in the fear of crime. Psychology, Crime and Law, 15 (4), 365-390. 
Jackson, J. P. (2008). Bridging the social and the psychological in the fear of crime. In M. Lee \& S. Farral (Eds.), Fear of crime: Critical voices in an age of anxiety (143-167). UK: Routledge.

Jackson, J. (2004). Experience and expression. Social and cultural significance in the fear of crime. British Journal of Criminology, 44, 946-966.

Jackson, J. P., Allum, N., \& Gaskell, G. (2006). Bridging levels of analysis in risk perception research: The case of the fear of crime. Forum qualitative Social research. 7(1), Art.20.

Jackson, J., Gray, E., \& Brunton-Smith, I. (2010). Decoding Disorder: On Public Sensitivity to Low-Level Deviance (March 10, 2010). Available at SSRN: http://dx.doi.org/10.2139/ssrn.1567953

Killias, M. (1990). Vulnerability: Towards a better understanding of a key variable in the genesis of fear of crime. Violence and victims, 5(2), 97-108.

Klinke, A., \& Renn, O. (2002). A new approach to risk evaluation and management: Risk-based, precaution based, and discourse based strategies. Risk Analysis, 22 (6), 1071-1094.

Kuo, F. E. \& Sullivan, W. C. (2001). Environment and crime in the Inner city: Does vegetation reduce crime? Environment and Behavior, 33(3), 343-367.

Kuo, F. E., Bacaicoa, M. \& Sullivan, W. C. (1998). Transforming Inner-City landscapes. Trees, sense of safety and preference. Environment and Behavior. 30 (1), 28-59.

LaGrange, R. L., Ferraro, K. F. \& Supancic, M. (1992). Perceived risk and fear of crime: role of social and physical incivilities. Journal of Research in Crime and Deliquency. 29(3), 311-334. 
Markowitz, F. E., Bellair, P. E., Liska, A. \& Liu, J. (2001). Extending Social Disorganisation Theory: Modeling the relationships between cohesion, disorder and fear. Criminology, 39 (2), 293-319.

Merry, S.E. (1981). Defensible space undefended. Urban Affairs Quarterly, 16(4), 397-422.

Miceli, R., Roccato, M. \& Rosato, R. (2004). Fear of crime in Italy. Environment and behaviour, 36(6), 776-789.

Nasar, J. L. (1998). The evaluative image of the city. London: SAGE Publications.

Otway, H. J. \& Von Winterfeldt, D. (1982). Beyond acceptable risk: On the social acceptability of Technologies. Policy Sciences, 14, 247-256.

Peinter, K. (1996). The influence of street lighting improvements on crime, fear and pedestrian street use, after dark. Landscape and Urban Planning, 35, 193-201.

Perkins, D.D. \& Taylor, R. B. (1996). Ecological assessments of community disorder: Their relationship to fear of crime and theoretical implications. American Journal of Community Psychology, 24, 63-107.

Pidgeon, N. (1998). Risk assessment, risk values and the social science programme: why do we need risk perception research. Reliability Engineering and System Safety, 59, 5-15.

Pidgeon, N. F. \& Beattie, J. (1997). The psychology of risk and uncertainty. In P. Calow (Ed.), Handbook of environmental risk assessment management (pp. 289-318). Oxford: Blackwell.

Pidgeon, N., Hood, C., Jones, D., Turner, B. \& Gibson, R. (1992) Risk perception. In The Royal Society (Ed.), Risk: Analysis, perception and management. London: The Royal Society. 
Pitner, R.O., Yu, M.,\& Brown, E. (2012). Making neighborhoods safer: Examining predictors of residents' concerns about neighborhood safety. Journal of Environmental Psychology, 32, 43-49

Pitner R. O. \& Astor, R. A. (2008). Children’s reasoning about poverty, physical deterioration, danger, and retribution in neighbourhood contexts. Journal of Environmental Psychology, 28, 327-338.

Power, M., \& Dalgleish, T. (1997). Cognition and emotion: From order to disorder. UK: Psychology Press. 1-13, 199-255 pp.

Preacher K. J. \& Hayes, A. F. (2004). SPSS and SAS procedures for estimating indirect effects in simple mediation models. Behaviour Research Methods, Instruments, \& Computers, 36(4), 717-731.

Renn, O. (1998). Three decades of risk research: Accomplishments and new challenges. Journal of Risk research, 1 (1), 49-71.

Rohrmann, B. (1998). The risk notion: epistemological and empirical considerations. In M. G. Stewart and R. E. Melchers (Eds.): Integrated risk assessment (3946). Rotterdam: Balkema.

Ross, C. E., Reynolds, J. R. \& Geis, K. J. (2000). The contingent meaning of neighbourhood stability for resident's psychological well-being. American Sociological Review, 65 (4), 581-597.

Sampson (2009). Disparity and diversity in the contemporary city: social (dis)order revisited. The British Journal of Sociology, 60 (1), 1-31.

Sampson R.J., \& Raudenbush, S. W. (2005). Neighbourhood stigma and the perception of disorder. Focus, 24 (1), 7-11. 
Sampson R.J., \& Raudenbush, S. W. (2004). Seeing disorder: Neighbourhood stigma and the social construction of "broken windows", Social Psychology Quarterly, 67, 319-342

Sampson R.J., \& Raudenbush, S. W. (1999). Systematic Social Observation of Public Spaces: A New Look at Disorder in Urban Neighborhoods. American Journal of Sociology, 105 (3), 603-51.

Schütz, H., Holger, \& Wiedemann, P. M. (2000). Risk Perception, beyond the Psychometric Paradigm. Retrieved from http:॥www.fz-juelich.de/mut/publikationen/liste_riko.html. File: heft_78.pdf

Schweitzer, J. H., Woo-Kim, J. \& Mackin J. R. (1999). The impact of the built environment on crime and fear of crime in urban neighbourhoods. Journal of urban technology, 6 ( 3), 59-73.

Semmens, N. (2004). The intangible costs of crime: Why the fear of crime causes us a problem. Paper to the second ESRC seminar on "Crime, insecurity and wellbeing: an economic approach”. Sheffield, 18 May, 2004. Unpublished paper obtained from the author.

Skogan, W. G. (1990). Disorder and decline: Crime and the spiral of decay in American neighbourhoods. Los Angeles: University of California Press.

Slovic, P. (1987). Perception of risk. Science. 236(4799), 280-285.

Slovic, P. (1992). Perception of Risk: Reflections on the psychometric paradigm. In S. Krimsky nad D. Golding (Eds.), Social theories of risk (117-152). Wesport: Praeger.

Slovic, P. (1998). The risk game. Reliability Engineering and System. Safety, 59, 7377. 
Slovic, P., \& Peters, E. (2006). Risk perception and affect. Current Directions in Psychological Science, 15, 322-325.

Slovic, P., Finucane, M. L., Peters, E., \& MacGregor D. G. (2004). Risk as Analysis and risk as feelings: Some thoughts about affect, reason, risk and rationality. Risk Analysis, 24 (2), 311-321.

Slovic, P. \& Weber, E. (2002). Perceptions of risk posed by extreme events. Paper prepared for discussion at the conference "Risk management strategies in an uncertain world”, Palisades, New York. April 12-13.

Taylor, R. B. (1987). Toward an environmental psychology of disorder: delinquency, crime, and fear of crime. In D. Stokols \& I. Altman (Eds.) Handbook of Environmental Psychology (pp. 951-986). New York: John-Wiley \& Sons.

Taylor, R. B. (1996). Neighbourhood responses to disorder and local attachments: The systemic model of attachment, social disorganization, and neighbourhood use value. Sociological Forum, 11(1), 41-74.

Thompson, P. B. \& Dean, W. (1996). Competing conceptions of risk. Retrieved from http://www.piercelaw.edu/risk/vol17/fall/thompson.htm

Tversky \& Kahneman (1982). Judgement under uncertainty: Heuristics and biases. In D. Kahneman, P. Slovic, \& A. Tversky (Eds.), Judgement under uncertainty: Heuristics and biases (pp 3-20). London: Cambridge University Press

Tversky \& Kahneman, (1974). Judgement under uncertainty: Heuristics and biases. Science, 185, 1127-1131.

Uzzell, D. \& Brown, J. (2007) 'Conceptual progress in understanding fear of crime in railway stations, Psicologia, 21, 2, $119-137$

Van der Pligt, J. (1998). Perceived risk and vulnerability as predictors of precautionary behaviour. British Journal of Health Psychology, 3 (1), 1-14. 
Walkalate, S. (1998). Crime and Community: Fear or Trust? The British Journal of Sociology, 49(4), 550-569.

Warr, M. (1987). Fear of victimization and sensitivity to risk. Journal of Quantitative Criminology, 3(1), 29-46.

Warr, M. (1984) 'Fear of victimisation: Why are women and the elderly more afraid?' Social Science Quarterly, 65, 681-702.

Weinstein, N. D., (1989). Optimistic biases about personal risks. In R. Lofstedt and L. Frewer (Eds.): Risk and modern society (239-241). London: Earthscan Publicactions Ltd.

Weyman, A. K. \& Kelly, C. J. (1999). Risk perception and risk communication: A review of the literature. A report prepared by the Health and Safety Laboratory, for the Health and Safety Executive, Sheffield. 248/1999.

Wilcox-Rountree, P. \& Land, K. C. (1996). Perceived risk versus fear of crime: Empirical evidence of conceptually distinct reactions in survey data. Social Forces, 74(4): 1353-1376.

Wilson, J. Q. \& Kelling, G. L. (1982). Broken windows. Atlantic Monthly, 211, 29-38 Wilson, J. Q. (1975). Thinking about Crime. Basic Books; New York.

Wyant, B. R. (2008). Multilevel impacts of perceived incivilities and perceptions of crime risk on fear of crime: Isolating endogenous impacts. Journal of Research on Crime and Delinquency, 45 (1), 39-64. 
Appendix A. Dimensions to measure perceived physical and social disorder, risk and safety.

\begin{tabular}{|c|c|c|c|c|c|}
\hline DIMENSION & SUBSCALE & ITEMS & $\begin{array}{l}\text { Petén } \\
\text { Degraded } \\
\text { Cronbach's } \\
\text { alpha } \\
\end{array}$ & $\begin{array}{l}\text { Petén } \\
\text { as Is } \\
\text { Cronbach's } \\
\text { alpha } \\
\end{array}$ & $\begin{array}{l}\text { Petén } \\
\text { Improved } \\
\text { Cronbach's } \\
\text { alpha } \\
\end{array}$ \\
\hline \multirow[t]{2}{*}{$\begin{array}{l}\text { PERCEIVED } \\
\text { PHYSICAL } \\
\text { DISORDER }\end{array}$} & Maintenance & $\begin{array}{l}\text { The place is tidy } \\
\text { The place is dirty } \\
\text { The place is noisy } \\
\text { The place is well cared for } \\
\text { The place is run-down } \\
\text { The place needs to be repaired } \\
\text { It is a green looking place }\end{array}$ & 0.70 & 0.84 & 0.81 \\
\hline & Prospect & $\begin{array}{l}\text { The place has good visibility } \\
\text { The place has clear pathways } \\
\text { I can clearly see what happens on the street } \\
\text { The place has traffic problems }\end{array}$ & 0.65 & 0.72 & 0.56 \\
\hline \multirow[t]{5}{*}{$\begin{array}{l}\text { PERCEIVED } \\
\text { SOCIAL } \\
\text { DISORDER }\end{array}$} & Deprivation & $\begin{array}{l}\text { The place is affluent } \\
\text { People might be poor } \\
\text { People might find life difficult } \\
\text { People might be living under crowded } \\
\text { conditions }\end{array}$ & 0.66 & 0.84 & 0.77 \\
\hline & $\begin{array}{l}\text { Community } \\
\text { involvement }\end{array}$ & $\begin{array}{l}\text { People might be friendly } \\
\text { People might be supportive } \\
\text { People like to be close to their neighbours } \\
\text { People take part in community life } \\
\text { People enjoy walking in the neighbourhood } \\
\text { People might be proud of living there } \\
\text { People look after their neighbourhood } \\
\text { People might be uninterested in what } \\
\text { happens there }\end{array}$ & 0.81 & 0.89 & 0.87 \\
\hline & Incivilities & $\begin{array}{l}\text { People might be harmful to others } \\
\text { People might be drug takers or alcoholic } \\
\text { People might be noisy neighbours } \\
\text { People might be trouble makers }\end{array}$ & 0.73 & 0.89 & 0.80 \\
\hline & Similarity & $\begin{array}{l}\text { People might be unpredictable } \\
\text { People might be similar to me } \\
\text { People share my moral values } \\
\text { It makes me feel at home } \\
\text { People might be reliable } \\
\text { People trust in each other }\end{array}$ & 0.78 & 0.86 & 0.84 \\
\hline & Likeability & $\begin{array}{l}\text { The place is nice } \\
\text { The place is attractive } \\
\text { The place has pleasant residential roads } \\
\text { The place is desirable }\end{array}$ & 0.78 & 0.93 & 0.92 \\
\hline \multirow[t]{3}{*}{$\begin{array}{c}\text { RISK } \\
\text { PERCEPTION }\end{array}$} & $\begin{array}{r}\text { Perceived } \\
\text { Vulnerability }\end{array}$ & $\begin{array}{l}\text { Think nothing bad will happen to you } \\
\text { Think people would help you if you needed it } \\
\text { Think you might be attacked by a stranger } \\
\text { Think you would be in trouble if you get lost }\end{array}$ & 0.72 & 0.72 & 0.66 \\
\hline & $\begin{array}{r}\text { Perceived } \\
\text { Control }\end{array}$ & $\begin{array}{l}\text { Ask people for help if you think you are in } \\
\text { trouble } \\
\text { Feel able to handle any unexpected problem } \\
\text { (photo } 3 \text { only and instead of help3: } \\
\text { Avoid encounters with people around the } \\
\text { place) }\end{array}$ & 0.49 & 0.54 & 0.33 \\
\hline & $\begin{array}{r}\text { Perceived } \\
\text { Probability of } \\
\text { Occurrence }\end{array}$ & $\begin{array}{l}\text { Abandoned cars } \\
\text { Physical or verbal attacks by people } \\
\text { Litter on the streets } \\
\text { Mugging } \\
\text { Car thefts } \\
\text { Robberies } \\
\text { Rowdy teens } \\
\text { Burglaries } \\
\text { Public Drinking } \\
\text { Vandalism } \\
\text { Police officers around the place } \\
\text { Domestic violence } \\
\text { Street fights }\end{array}$ & 0.86 & 0.92 & 0.89 \\
\hline Safety & $\begin{array}{r}\text { Perceived } \\
\text { Safety }\end{array}$ & $\begin{array}{l}\text { Feel confident while walking there } \\
\text { Feel secure because it is an unthreatening } \\
\text { place } \\
\text { Be worried about the possibility of } \\
\text { victimization } \\
\text { Feel unease because you don't know what to } \\
\text { expect }\end{array}$ & 0.78 & 0.83 & 0.83 \\
\hline
\end{tabular}


Table 4. Standard Multiple Regression on Perceived Safety for Peten Street Degraded

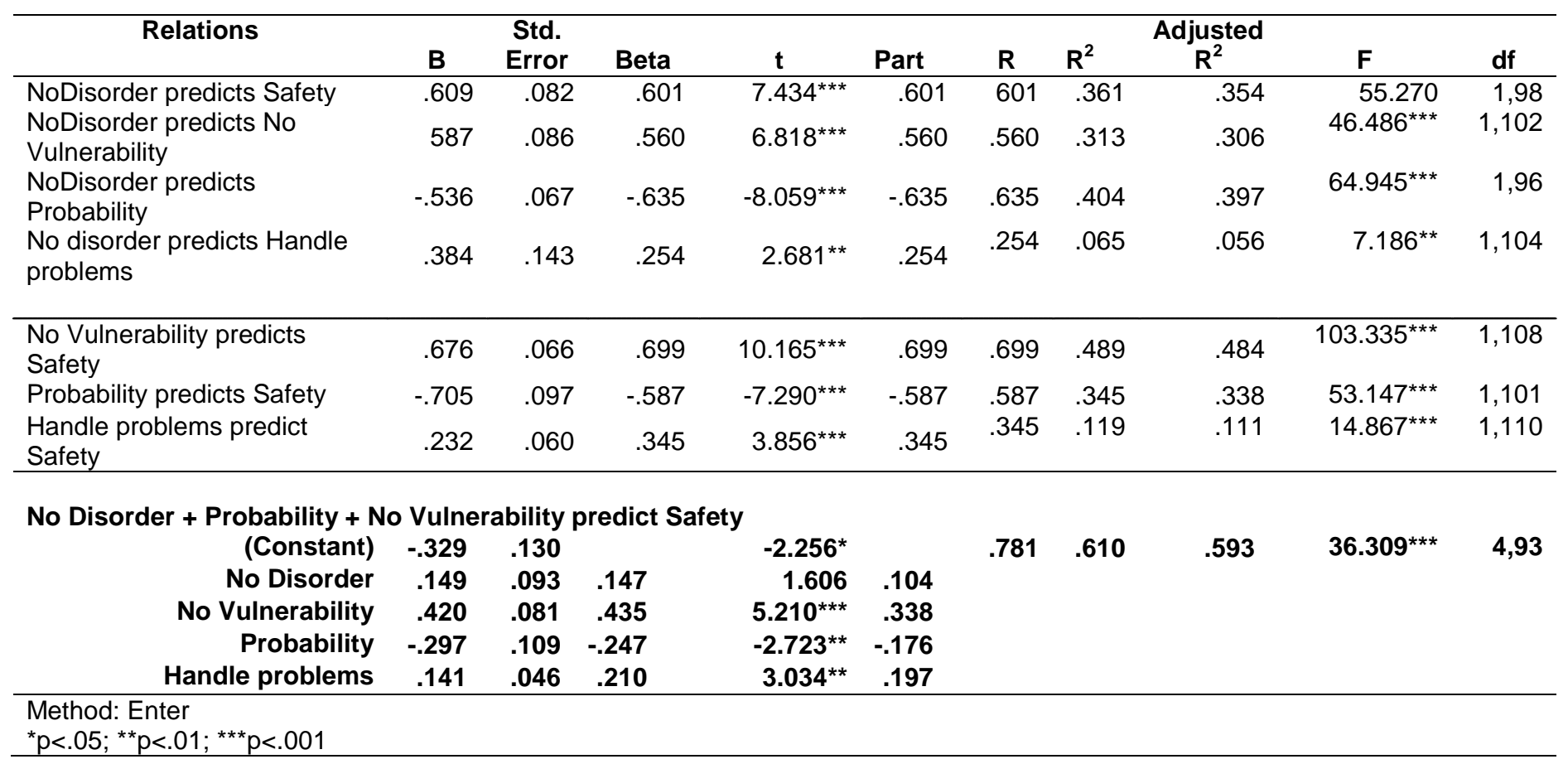


Table 6. Standard Multiple Regression on Perceived Safety for Petén Street as It Is

\begin{tabular}{|c|c|c|c|c|c|c|c|c|c|c|}
\hline & B & $\begin{array}{l}\text { Std. } \\
\text { Error }\end{array}$ & Beta & $t$ & Part & $\mathbf{R}$ & $\mathbf{R}^{2}$ & $\begin{array}{l}\text { Adjus } \\
\text { ted } R^{2}\end{array}$ & $\mathbf{F}$ & df \\
\hline No Disorder predicts Safety & .651 & .068 & .696 & $9.593^{\star \star \star}$ & .696 & .696 & .484 & .479 & $92.035^{\star \star \star}$ & 1,98 \\
\hline $\begin{array}{l}\text { No Disorder predicts No } \\
\text { Vulnerability }\end{array}$ & .485 & .060 & .624 & $8.061^{\star \star \star}$ & .624 & .624 & .389 & .383 & $64.974^{\star \star \star}$ & 1,102 \\
\hline $\begin{array}{l}\text { No Disorder predicts } \\
\text { Probability }\end{array}$ & -.510 & .055 & -.685 & $-9.205^{\star \star \star}$ & -.685 & .685 & .469 & .463 & $84.738^{\star * *}$ & 1,96 \\
\hline $\begin{array}{l}\text { No disorder predicts Handle } \\
\text { problems }\end{array}$ & .375 & .111 & .315 & 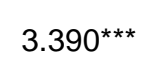 & .315 & .315 & .100 & .091 & $11.495^{\star \star *}$ & 1,104 \\
\hline $\begin{array}{l}\text { No Vulnerability predicts } \\
\text { Safety }\end{array}$ & .784 & .088 & .652 & $8.933^{\star \star \star}$ & .652 & .652 & .425 & .420 & $79.807^{\star \star \star}$ & 1,108 \\
\hline Probability predicts Safety & -.708 & .103 & -.565 & $-6.875^{\star \star \star}$ & -.565 & .565 & .319 & .312 & $47.262^{\star \star \star}$ & 1,101 \\
\hline $\begin{array}{l}\text { Handle problems predict } \\
\text { Safety }\end{array}$ & .342 & .068 & .435 & $5.071^{\star * \star}$ & .435 & .435 & .189 & .182 & $25.711^{\star \star *}$ & 1,110 \\
\hline No Disorder - & ulner & y pred & afety & & & & & & & \\
\hline (Constant) & .111 & .044 & & $2.510^{*}$ & & .777 & .604 & .587 & $35.534^{\star \star *}$ & 4,93 \\
\hline No Disorder & .292 & .099 & .312 & $2.945^{\star *}$ & .192 & & & & & \\
\hline No Vulnerability & .352 & .107 & .293 & $3.276^{* * *}$ & .214 & & & & & \\
\hline Probability & -.268 & .113 & -.214 & $-2.366^{*}$ & -.154 & & & & & \\
\hline Handle problems & .137 & .058 & .175 & $2.357^{*}$ & .154 & & & & & \\
\hline
\end{tabular}

Method: Enter

${ }^{*} \mathrm{p}<.05 ;{ }^{* \star} \mathrm{p}<.01 ;{ }^{* \star *} \mathrm{p}<.001$

Table 7. Standard Multiple Regression on Perceived Safety for Peten Street Improved

\begin{tabular}{|c|c|c|c|c|c|c|c|c|c|c|}
\hline & B & $\begin{array}{l}\text { Std. } \\
\text { Error }\end{array}$ & Beta & $\mathbf{t}$ & Part & $\mathbf{R}$ & $\mathbf{R}^{2}$ & $\begin{array}{l}\text { Adjus } \\
\text { ted } R^{2}\end{array}$ & $\mathbf{F}$ & df \\
\hline No Disorder predicts Safety & .518 & .074 & .576 & $6.976^{\star \star \star}$ & .576 & .576 & .332 & .325 & $48.661^{\star \star \star}$ & 1,98 \\
\hline No Disorder predicts No Vulnerability & .478 & .074 & .540 & $6.484^{\star \star \star}$ & .540 & .540 & .292 & .285 & $42.048^{\star \star \star}$ & 1,102 \\
\hline No Disorder predicts Probability & -.542 & .056 & -.701 & $-9.624^{\star \star \star}$ & -.701 & .701 & .491 & .486 & $92.628^{\star \star \star}$ & 1,96 \\
\hline No Disorder predicts Handle problems & .329 & .126 & .248 & $2.610^{\star *}$ & .248 & .248 & .061 & .052 & $6.815^{\star \star}$ & 1,104 \\
\hline No Vulnerability predicts Safety & .675 & .073 & .664 & $9.238^{\star \star \star}$ & .664 & 664 & .441 & .436 & $85.332^{\star \star \star}$ & 1,108 \\
\hline Probability predicts Safety & -.576 & .100 & -.496 & $-5.737^{\star \star \star}$ & -.496 & .496 & .246 & .238 & 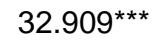 & 1,101 \\
\hline Handle problems predicts Safety & .208 & .061 & .307 & $3.388^{\star \star \star}$ & .307 & .307 & .094 & .086 & $11.476^{\star \star \star}$ & 1,110 \\
\hline \multicolumn{11}{|c|}{ No Disorder + Probability + No Vulnerability predict Safety } \\
\hline (Constant) & .337 & .120 & & $2.812^{\star *}$ & & .716 & .513 & .492 & $24.449 * * *$ & 4,93 \\
\hline No Disorder & .239 & .097 & .266 & $2.460^{*}$ & .178 & & & & & \\
\hline No Vulnerability & .471 & .096 & .463 & $4.911^{\star * *}$ & .356 & & & & & \\
\hline Probability & -.070 & .126 & -.061 & -.559 & -.040 & & & & & \\
\hline Handle problems & .048 & .054 & .070 & .876 & .063 & & & & & \\
\hline
\end{tabular}

